tion of waves, direction finding, the measurement and means of suppression of the various types of interfering noise experienced in radio reception, and the improvement of transmitters, particularly from the point of view of frequency stability and the consequent reduction of inter-station interference. Other matters which will be discussed at Bucharest, and upon which it is evidently desirable to secure the greatest measure of international agreement, concern the allocation of wave-bands to the various types of radio-communication services, and the nomenclature employed in designating these wave-bands and the corresponding frequency ranges. It is anticipated that some twenty nations will participate in the Bucharest conference, and the British delegation will include representatives of the Post Office, National Physical Laboratory, British Broadcasting Corporation and the various manufacturing and operating companies.

\section{Magnetic Disturbances and Auroras}

Wrmxng with reference to the notes on this subject in NATURE of May 8, p. 790, Father J. P. Rowland states: "I greatly regret that by inadvertence I misread in my notes a horizontal force range in minutes of arc, before converting into gammas, as a declination range, and so gave the extreme declination range as $93^{\prime}$, whereas it should be $62^{\prime}$ as given in my letter to The Times. The extreme range in horizontal force, exceeding $620 \gamma$ is correct. There was another notable magnetic disturbance from May $4^{\mathrm{d}} 17^{\mathrm{h}}$ to $5^{\mathrm{d}} 18^{\mathrm{h}}$ U.T. with ranges in declination and horizontal force of $28^{\prime}$ and $234 \gamma$ respectively, probably associated with an elongated group of sunspots which crossed the central meridian on April 29."

\section{Comets}

Mr. L. E. CunnINGHam at Harvard has detected the periodic comet Grigg -Skjellerup. Its position on April $30^{\mathrm{d}} 1^{\mathrm{h}} 30^{\mathrm{s}}$ U.T. was R.A. $6^{\mathrm{h}} 59^{\mathrm{m}} 0^{\mathrm{s}}$, N. Decl. $7^{\circ} 53^{\prime} 27^{\prime \prime}$, mag. 13. In the "B.A.A. Handbook" for 1937 the elements and also an ephemeris are given, perturbations being taken into account. Comparison with this ephemeris indicates that perihelion will be reached on May 23.0 U.T., which is about half a day later than the predicted time. Dr. M. Davidson has used observations from February 4 to April I, forming normal positions, and finds that Comet $1937 b$ (Whipple) is moving in an elliptic orbit with eccentricity 0.999619 . The period is very long-about 300,000 years.

\section{Announcements}

A $r$ the request of the Council of the Royal Society of Edinburgh and in terms of the Bruce-Preller Lecture Fund, Prof. H. S. Taylor, of the Department of Physical Chemistry, Princeton University, will deliver an address on "Heavy Hydrogen in Scientific Research", at the ordinary meeting of the Society to be held on June 7 .
DR. W. T. K. Brauntourz has been appointed secretary of the Institution of Gas Engineers in succession to Mr. J. R. W. Alexander, who has been appointed general manager of the Associated Gas and Water Undertakings, Ltd., and of the East Surrey Gas Co.

Johnstone and Florence Stoney studentships of the value of $£ 250$ each for research in Australia have been awarded by the British Federation of University Women to Miss Mary Elizabeth King and to Miss Joyce Laing, who are both proposing to work on aspects of pathology. A similar studentship will be offered for the year 1938-39.

THE annual congress of the Royal Institute of Public Health in conjunction with the Institute of Hygiene will be held at Margate on May 25-29 under the presidency of Lord Horder. Further information can be obtained from the Secretary, A. Seymour Harding, 28 Portland Place, London, W.I.

The French Academy of Medicine has awarded the Albert I of Monaco prize of 100,000 francs to Drs. Paul Bouin and Ancel for their work on the sex hormones and the interstitial glands in man.

Prof. Levaorrr, of the Paris Pasteur Institute and member of the Academy of Medicine, has been nominated scientific director of the French League against the Venereal Peril.

The National Geographic Society announces by its News Bulletin that arrangements are being made to broadcast on June 8 a description of the total solar eclipse of June 9 next from either Canton or Enderby Island in the Central Pacific. The transmission will probably be from an anchored vessel, and will begin from time to time several weeks previous to the eclipse with a description of the preparations.

Messrs. Bernard Quaritce, Lto., 11 Grafton Street, London, W.1, have issued a Catalogue (No. $531,1937)$ of books on early medicine and surgery. The gem of the collection is a fine copy of the very rare first edition of William Harvey's "Exercitatio Anatomica De Motu Cordis", printed in Frankfort in 1628. Among other rare and interesting works listed may be mentioned Robert Wyer's "Antidotharius", containing recipes for plasters, salves, ointments, etc., J. Duchesne's "The Practise Of Chymicall and Hermeticall Physicke", William Turner's "Herbal", and a copy of the second edition of Jenner's "An Inquiry into the Causes and Effects of the Variolæ Vaccinæ".

Erratum.-In the course of the summary of the Huxley Memorial Lecture delivered by Sir Thomas Holland printed in NATURE of May 8, p. 809, reference is made to the work of "W. T. Blandford". The name should, of course, have been "W. T. Blanford"; and we regret having overlooked the mistake made in the typed summary supplied to us and followed by our printers. 